\title{
O PROCESSO DA CONSTRUÇÃO DA LINGUAGEM E DO PENSAMENTO DA CRIANÇA
}

\author{
Adriane de Lima Vilas Boas Bartz ${ }^{1}$
}

\begin{abstract}
Resumo: A pesquisa evidenciou que o desenvolvimento da linguagem tem um processo longo, onde ocorrem vários estudos que levantam concepções para que tenha uma melhor compreensão do seu surgimento. Esse processo tem três mudanças citadas por Vygotsky: a criança começa a usar a memória lógica e no desenvolvimento da fala este estágio é o da fala interior, silenciosa; a linguagem nasce por imitação. O aprendizado é o processo da maturação e da compreensão do indivíduo com o meio, nessa fase ela tem comando da verbalização e a mesma pode interagir com os objetos, nomeando-os. $O$ desenvolvimento da escrita na criança para Vygotsky é um novo marco e um grande salto no desenvolvimento da pessoa, ele também enfatiza que não é somente através da linguagem falada que um indivíduo pode se relacionar com o mundo, mas sim através do aprendizado da linguagem escrita. Ao buscar entender o desenvolvimento da escrita na criança, assim a aprendizagem das crianças acontece mesmo antes de entrarem na escola.
\end{abstract}

Palavras Chave: linguagem; pensamento; aprendizagem; mediação; educação infantil.

\section{THE CHILD'S LANGUAGE AND THINKING CONSTRUCTION PROCESS}

\begin{abstract}
The research evidenced that the development of language has a long process, where several studies occur that raise concepts so that it has a better understanding of its emergence. This process has three changes cited by Vygotsky: the child begins to use logical memory and in the development of speech this stage is that of silent, inner speech; language is born by imitation. Learning is the process of maturation and understanding of the individual with the environment, at this stage it has command of the verbalization and it can interact with the objects, naming them. The development of writing in the child for Vygotsky is a new milestone and a great leap in the development of the person, he also emphasizes that it is not only through spoken language that an individual can relate to the world, but through learning the written language. In seeking to understand the development of writing in the child, so the learning of children happens even before they enter school.
\end{abstract}

Keywords: language; thought; learning; mediation; child education.

\section{Introdução}

Esta pesquisa evidencia o processo de desenvolvimento e aprendizagem na educação infantil mediada pela linguagem segundo a teoria vygotskyana. Nessa perspectiva buscou a teoria Histórico-Cultural para levantar dados que possam contribuir na construção e compreender o desenvolvimento adquirido da linguagem pela criança, destaca a linguagem como uma das atividades principais quando a criança se encontra em contato com o meio, isto é, através da sua interação e na idade pré-escolar, uma vez que, por intermédio dessa atividade, ocorrem as mais importantes e significativas mudanças no desenvolvimento psíquico da criança.

É fundamental reforçar a relação que envolve a educação das crianças com a brincadeira e através da mediação do professor, onde ele possa colaborar com as necessidades das crianças na fase que se encontra de desenvolver a linguagem, na busca de superar a compreensão que se tem sobre esse tema. O homem possui vários modos para se comunicar que foram evoluindo com o passar dos tempos e com a própria história humana. Entre eles destacam-se as linguagens

\footnotetext{
${ }^{1}$ Docente do curso de Pedagogia da Faculdade Dom Bosco de Ubiratã. E-mail: dri_bartz@ @otmail.com
} 
faladas, escritas e gestuais que são produzidas através de gravuras, pinturas, sons, desenhos, símbolos e signos.

A linguagem é o mecanismo fundamental da comunicação e inserção de prática nas atividades comunicativas humanas. $\mathrm{O}$ ato de comunicar está relacionado ao fato de tornar algo comum, conhecido, que encontrou no uso da linguagem fator de destaque, fazendo com que esta exerça, sobre os demais modos, assim, tem-se na linguagem humana a capacidade de comunicação que se estabelece por meio de uma língua.

Dessa maneira, busca-se evidenciar a importância da linguagem e através de intervenções que se podem proporcionar o desenvolvimento das funções psicológicas cognitivas juntamente com o pensamento (atenção, concentração, memória, percepção e raciocínio), as quais colaboram na manifestação da criatividade, e da imaginação e possam contribuir para que o indivíduo tenha uma boa interação com o meio colaborando com o seu desenvolvimento e sua aprendizagem. Enfim, é preciso entender o desenvolvimento dessas linguagens na criança para que assim o educador possa trabalhar de uma maneira mais completa, valorizando o aprendizado infantil.

\section{A Construção da Linguagem e do Pensamento da Criança}

Por volta dos anos sessenta Chomsky investiga as etapas cognitivas e seus pré-requisitos para o nascimento da linguagem. Afirma também, que o que distingue a natureza do homem das outras espécies é a linguagem, que consiste em uma capacidade excepcionalmente humana. Se ela for natural, as palavras têm uma definição própria e imprescindível; se for convencional, são determinações consensuais do meio e, nesse caso, são eventuais, isto é, o ser humano poderia ter selecionado outras palavras para nomear os objetos. Em contrapartida o pensamento é a representação da realidade.

Chamamos pensamento, em sentido próprio, o processo de reflexo consciente da realidade, nas suas propriedades, ligações e relações objetivas, incluindo os mesmos objetivos inacessíveis à percepção sensível imediata. O homem, por exemplo, não percebe os raios ultravioletas, mas nem por isso desconhece a sua existência e as suas propriedades. Que torna possível este conhecimento? Ele é possível por via do pensamento. O seu princípio geral é que submetemos as coisas à prova de outras coisas e, tomando consciência das relações e interações que se estabelecem entre elas, julgamos a partir das modificações que aí percebemos as propriedades que nos não são diretamente acessíveis [...] (LEONTIEV, 1998, p.84).

De acordo com os autores acima citados, o pensamento é o meio pelo qual o homem se diferencia dos demais animais, porque tem a habilidade de raciocinar e tomar decisões mais 
precisas nos momentos de extrema necessidade, quando existe um prenúncio contra sua existência, por exemplo, desde que nascemos possuímos nossas defesas.

A conquista da linguagem representa um marco no desenvolvimento do homem a capacitação especificamente humana para a linguagem habilita as crianças a providenciarem instrumentos auxiliares na solução de tarefa difíceis, a superarem a ação impulsiva, a planejarem a solução para um problema antes de sua execução e a controlarem seu próprio comportamento. (VYGOTSKY, 1987, apud REGO 2001, p. 63).

Vygotsky (2003), então sugere a teoria sobre o desenvolvimento humano, na qual analisa não só a construção integral do sujeito, mas da espécie humana em geral. A linguagem é o meio de comunicação que possibilita a interação com o meio social através da expressão e compreensão de ideias e também o próprio domínio para controlar a própria conduta.

A linguagem é um sistema de signos que possibilita o intercâmbio social entre os indivíduos que compartilhem desse sistema de representação da realidade. [...] É justamente por fornecer significados precisos que a linguagem permite a comunicação entre os homens (REGO, 2001, p. 54).

Para que essa comunicação ocorra de forma clara e compreensível o pensamento deve estar ligado com a fala, isto é para que possa haver a associação entre o significado e significante deve expressar o pensamento através da linguagem.

Segundo Baquero (1998, apud Vygotsky, 1934, p.21) “a função inicial da linguagem é comunicativa. A linguagem antes de tudo um meio de comunicação social, um meio de expressão e compreensão".

Ainda para Vygotsky a linguagem tem duas funções básicas para a formação dos conceitos que são elas a de intercambio social e a de pensamento generalizante, isto é o pensamento através da linguagem servem para a comunicação entre os indivíduos e para ordenar a própria realidade.

Para tanto, o estudo fundamentou-se no desenvolvimento da linguagem e do pensamento, focando na importância da interação social e da mediação para o desenvolvimento das funções mentais superiores. Colaborando assim, para o entendimento dos processos de desenvolvimento humano, mais designadamente para a captação do processo de aprendizagem.

Ao averiguar o desenvolvimento da linguagem e do pensamento segundo esse mesmo autor, ressalta-se que são dois os elementos estruturantes da palavra: a função designativa e o significado. O primeiro item incide na inclusão da palavra como designadora ou nomeadora de objetos, pessoas, ações, entre outros, enquanto que o segundo consiste na admissão do isolamento de determinados aspectos do objeto, sua generalização e a probabilidade de adentrarse em sistemas de categoria. 
O autor ainda complementa que a criança principia aplicando a palavra com a função de nomeação, o incremento das suas funções dependerá das afinidades de interação com adultos ou com outras crianças mais espertas. Tal desenvolvimento desencadeará a aprendizagem, que permitirá a menção de determinados objetos.

Esta aprendizagem se desponta nas respostas e reações oferecidas pelo adulto de acordo com o autor. Por exemplo, quando a criança volta os olhos ou arrisca-se para alcançar um objeto determinado pelo adulto ela evidencia dependência aos seguintes fatores: situacional, relacional e emocional. Dessa maneira, quando a criança estabelece um código estável, apesar de ainda estar vinculado à prática, faz uso das palavras transcrevendo as dos adultos. Pode-se destacar que neste período as palavras têm significado sombrio de acordo com a situação.

Para Vygotsky (2003, p. 117-118). “[...] o aprendizado desperta vários processos internos de desenvolvimento que são capazes de operar somente quando a criança interage com pessoas em seu ambiente e quando em cooperação com seus companheiros". Por meio dos experimentos e interações com os sentidos atribuídos, a criança se apropria do uso do símbolo em uma determinada ocorrência e recebe uma referência constante, que poderá ser usual para diversas situações ultrapassando a reprodução.

Cole et al (2003, p. 9), "os sistemas de signos [...], assim como o sistema de instrumentos, são criados pelas sociedades ao longo do curso da história humana, mudam a forma social e o nível de desenvolvimento cultural". Para os autores, esta aprendizagem sucede por meio da interiorização dos sentidos e uso das categorias das palavras e das propriedades dos objetos.

A definição da palavra principia o seu desenvolvimento e este processo se torna reconhecido no período em que a criança passa a referir-se aos objetos sem necessitar dos meios que antes eram decisivos para sua reação. Isto é constante na educação infantil, quando sua menção já se encontra assente, tornando admissível e aprimorada a comunicação da criança e o entrosamento da comunicação para os outros.

Pode-se avaliar, de acordo com a Teoria Vygotskyana, que na etapa em que as crianças se habituam a empilhar objetos elas operam emotivamente no que se menciona à comunicação e à linguagem por permanecerem admitindo o mundo e principiando sua construção da realidade. Por fim, na fase das aglomerações, a criança distancia sua fala e pensamento da atuação prática, autorizando a generalização e a abstração.

[...] as funções psicológicas têm um suporte biológico, pois são produtos da atividade cerebral; o funcionamento psicológico fundamenta-se nas relações sociais entre indivíduo e o mundo exterior, as quais desenvolvem-se num 
processo histórico; a relação homem / mundo é uma relação mediada por sistemas simbólicos [...] (VYGOTSKY, apud. OLIVEIRA, 1994, p.23).

Desta forma, o pensamento por complexo é pensamento prático, o qual restringe a criança no uso do utensílio apenas prontamente ligado a ação, pois tem como propriedades a inteligência prática, a linguagem emocional e não permite que a criança abstraia e generalize.

Conforme dado momento, a criança procura estabelecer afinidades entre os subsídios da realidade, agregando admirações dispersas, para que depois estas relações palpáveis, envolvam uma maior probabilidade de análise e generalização dos objetos. Ao obterem o potencial, as crianças instalam os conceitos e significados, este se conforma e diferencia-se como sendo a união entre a linguagem e o pensamento.

A relação entre pensamento e linguagem modifica-se no processo de desenvolvimento tanto no sentido quantitativo quanto no qualitativo. Noutros termos, o desenvolvimento da linguagem e do pensamento realiza-se de forma não paralela e desigual. As curvas desse desenvolvimento convergem e divergem constantemente, cruzam-se, nivelam-se em determinados períodos [...] (VYGOTSKY, 2001, p.111).

Á partir desta definição, propõe-se uma teoria sobre o desenvolvimento humano, na qual avalia não só o desenvolvimento do indivíduo, mas também da espécie humana. Para tanto, o estudo fundamenta-se no desenvolvimento da linguagem e do pensamento, enfocando a importância da interação social e da mediação para o incremento das funções mentais superiores.

As funções psicológicas têm um suporte biológico, pois são produtos das atividades cerebrais, o funcionamento psicológico fundamenta-se nas relações sócias entre o indivíduo e o mundo exterior, a relação homem/mundo é medida por sistemas simbólicos (TENEIRO ET AL, apud VYGOTSKY, 2009, p.88).

Assim fornece o entendimento dos processos de desenvolvimento humano, mais designadamente para a captação do procedimento de aprendizagem. A definição da palavra principia seu desenvolvimento e este processo pode ser alcançado a partir do período que a criança começa a reagir seletivamente ao objeto sem, basicamente, depender dos fatores que antes eram categóricos para sua reação.

[...] é a distância entre o nível de desenvolvimento real, que se pode determinar através da solução independente de problemas, e o nível de desenvolvimento potencial, determinado através da solução de problemas sob orientação de um adulto ou em colaboração com companheiros mais capazes (VYGOTSKY, 2007, p. 97).

O autor acima evidenciou a zona de desenvolvimento proximal que de acordo com ele, é a distância entre o nível de desenvolvimento real, que se pode determinar por meio do recurso da autonomia para resolver problemas e o nível de desenvolvimento potencial, examinado por meio 
da solução de problemas com a supervisão de um adulto ou em cooperação com sujeitos mais capazes. Quando se fala em zona de desenvolvimento proximal, conclui-se que é por meio da integração e mediação com o adulto que a criança amplia suas aptidões comunicativas.

Esta zona de desenvolvimento proximal é definida pelo autor como, "aquelas funções que ainda não amadureceram, mas que estão em processo de maturação, funções que amadurecerão, mas que estão em estado embrionário". Caracteriza estes papéis como "brotos" ou "flores" do desenvolvimento e não frutos desse mesmo desenvolvimento. Assegura que o desenvolvimento mental da criança é determinado exclusivamente se os dois estados de desenvolvimento forem "revelados": o nível de desenvolvimento real e a zona de desenvolvimento proximal (VYGOTSKY, 2007, p.98).

Para entender melhor o que seria a mediação, Oliveira analisa a elucidação do tema e posteriormente conceitua-o. Oliveira, (2008, p.26) "Mediação é o processo de intervenção de um elemento intermediário numa relação; a relação deixa, então de ser direta e passa a ser mediada por esse elemento".

Portanto, quando uma pessoa apropria-se de uma experiência prévia para determinar uma nova tese ele está dirigindo sua própria memória, assim observa-se uma pessoa que já tenha se queimado ao pôr a mão sobre a chapa quente de um fogão.

A autora complementa que na primeira vez que isto incidiu a resposta foi direta, quando a pessoa sentiu o calor da chapa ela afastou a mão, mas agora ela não necessita sentir o calor, a mão se queimando ou até mesmo há dor para extraí-la.

Esse ato foi uma obra mediada pela sua memória que agora tem uma marca do experimento vivido, não carecendo mais da chapa quente para imaginar o que poderia dar-se quando cometesse o mesmo. Assim, ao ouvir uma história sobre este assunto poderá acrescentar os resultados mesmo sem ter a presença física do fogão. Mas esta resposta não está atualizada na pessoa desde o seu nascimento, é indispensável que haja uma interação desta pessoa com as outras para que estas experiências, ou símbolos comecem a fazer parte de sua vida e proporcione significado, compondo desta forma o acréscimo dos processos mentais superiores.

Para acatar este fato é importante mencionar Oliveira (2008 p.33) que diz: “[...] justamente por constituírem funções psicológicas mais sofisticadas, os processos mediados irão ser construídos ao longo do desenvolvimento, não estando ainda presentes nas crianças pequenas". Na escola é plausível por meio da mediação dos professores que a criança alcance as relações entre a opinião que ela já possui e o científico correspondente ao da escola, por meio de condições e experiências vividas pela criança, fazendo com que ela aprenda a partir do que ela já sabe. Assim, o papel do professor é indispensável dentro do processo ensino aprendizagem porque é por meio de suas intervenções, de sua participação, de sua atuação direta unida à 
criança que poderá então dilatar seu pensamento e as suas funções psicológicas superiores que lhe permitirão legitimamente o aprendizado.

Assim, a linguagem tem o papel fundamental para desenvolver as características psicológicas e humanas, auxilia na organização e elaboração da história social permitindo que aconteça a interação entre a criança e o meio.

A linguagem é exibida segundo Vigotsky como instrumento mais sofisticado, é com ela que o homem consegue a interação com os outros homens, comunica suas necessidades, anseios, esperanças e alegrias, adequando um meio atuante também de capacitação. Luria, (1979, p.81). "A linguagem é o veículo fundamental de transmissão de informação", que se formou na história social da humanidade [...]. Dranka nos diz que segundo Vigotsky:

A linguagem é um dos mais poderosos meios de influência sobre a conduta do outro. O próprio homem, no processo de seu desenvolvimento, chega a dominar os mesmos meios que foram utilizados para orientar o seu comportamento (DRANKA, 2001, p.01).

É através da influência mutua que a pessoa vai adolescendo suas funções psicológicas superiores que lhe proporcionarão atributos para agir no mundo, essa ação está agregada ao ser na sociedade, compreendê-lo, modificá-lo, afinal ser legitimamente um homem com qualidades capaz de edificar sua própria história.

No trabalho epilinguístico completa-se então dados que surgem nos momentos em que o sujeito real pensa as atividades escritas, e mais designadamente com feitios da referenciação.

Como se formaram a palavra e a linguagem? No trabalho os homens entram forçosamente em relação, em comunicação uns com os outros. Originariamente, as suas ações, o trabalho propriamente, e a sua comunicação formam um processo único. Agindo sobre a natureza, os movimentos de trabalho dos homens agem igualmente sobre os outros participantes na produção. Isto significa que as ações do homem têm nestas condições uma dupla função: uma função imediatamente produtiva e uma função de ação sobre os outros homens, uma função de comunicação (LEONTIEV, 1959, apud OLIVEIRA, 1997, p.92).

Para ele as estruturas variáveis são maneiras de organização das atividades mentais, que englobam os aspectos motores ou intelectuais e afetivos, tanto na dimensão individual como na social; já as características invariáveis são as funções de interesse, explicação, entre outras, que não variam com o nível mental do indivíduo.

[...] a linguagem humana, sistema simbólico fundamental na medição entre sujeito e objeto de conhecimento, tem, para Vygotsky, duas funções básicas: a de intercâmbio social e a de pensamento generalizante. Isto é, além de servir ao propósito de comunicação entre indivíduos, a linguagem simplifica e generaliza a experiência, ordenando as instâncias do mundo real em categorias conceituais cujo significado é compartilhado pelos usuários dessa linguagem. Ao utilizar a linguagem para nomear determinado objeto estamos, na verdade, classificando 
esse objeto numa categoria, numa classe de objetos que têm em comum certos atributos. A utilização da linguagem favorece, assim, processos de abstração e generalização. (OLIVEIRA, 1992, p.27).

No momento das operações concretas, as percepções proferidas se modificam em operações, classificação, ordenamento, correspondência, além de se notar o nascimento dos elementos do tempo, causalidade, conservação, entre outras.

O elemento «cultural» da teoria de Vygotsky envolve os meios socialmente estruturados pelos quais a sociedade organiza os tipos de tarefas que a criança em crescimento enfrenta, e os tipos de instrumentos, tanto mentais como físicos, de que a criança pequena dispõe para dominar aquelas tarefas. Um dos instrumentos básicos inventados pela humanidade é a linguagem, e Vygotsky deu ênfase especial ao papel da linguagem na organização e desenvolvimento dos processos de pensamento (VYGOTSKY; LURIA \& LEONTIEV, 1988, p.26).

Todavia de acordo com os autores, o pensamento ainda continua com suas conexões ligadas ao mundo real, isto é, as operações se prendem as experiências sólidas, não compreendendo as operações de lógica de proposições ou, como convenciona os autores o pensamento concreto é a representação de um ato provável. Por sua vez, na adolescência, é conseguida a independência do real, passando a existir o período das operações formais.

Segundo os autores mencionados acima seu caráter geral é o modo de raciocínio, que não se baseia somente em objetos ou fatos evidentes, entretanto ainda em suposições, admitir, desta forma, a composição de reflexões e teorias. O pensamento aceita então hipotético-dedutivo e, segundo eles ocorrem à libertação do pensamento, quando o acontecimento torna-se secundário frente à expectativa.

Neste período, além da lógica de hipóteses, são desenvolvidas, entre outras, as combinatórias e de correspondência.

Para os autores, têm outros fatores básicos que são: Maturação, uma vez que este desenvolvimento é uma extensão da embriogênese; (formação embrionária). Em seguida o papel da Experiência contraída no meio físico sobre as estruturas da inteligência, e a transmissão Social numa definição aberta (transmissão linguística, educação, etc.); e um fator que constantemente é descuidado, no entanto é essencial. Designa-se esse fator de equilibração ou auto-regulação.

Quando a criança assimila a linguagem, fica apta a organizar de nova maneira a percepção e a memória; assimila formas mais complexas de relação sobre os objetos do mundo exterior; adquire a capacidade de tirar conclusões das suas próprias observações, de fazer deduções, conquista todas as possibilidades do pensamento (LURIA, 1991, p.80). 
Igualmente, vê-se que o amadurecimento é espécie imprescindível, na expectativa de ser uma prorrogação do processo de formação do homem, contudo não explica todo o desenvolvimento, desempenhando uma limitada função de abrir probabilidades para novos procedimentos que necessitam ser modernizado, o que facilmente leva à conceituação de outras categorias, das quais a mais rápida é a experiência.

Toda generalização, toda formação de conceitos é o ato mais específico, mais autêntico e indiscutível do pensamento. Consequentemente estamos autorizados a considerar o significado da palavra como um fenômeno do pensamento (VYGOTSKY, 2001, p.398).

Por outro lado, o desenvolvimento é uma busca constante de equilíbrio, que constitui a adequação dos planos existentes ao mundo externo.

\begin{abstract}
Quando os processos de desenvolvimento do pensamento e da linguagem se unem, surgindo então, o pensamento verbal e a linguagem racional, o ser humano passa a ter a possibilidade de um modo de funcionamento psicológico mais sofisticado, mediado pelo sistema simbólico da linguagem. É importante mencionar que, para Vygotsky, o surgimento dessa possibilidade não elimina a presença da linguagem sem pensamento verbal passa a predominar na ação psicológica tipicamente humana. (VIGOTSKY, apud, OLIVEIRA, 1997, p.47).
\end{abstract}

A linguagem, segundo o autor, cumpre ainda outro papel essencial, que saem dos limites da organização da percepção e da transmissão de informações. Sua presença e suas estruturas lógico-gramaticais permitem ao homem tirar suas próprias conclusões baseando-se em raciocínios lógicos, sem precisar se dirigir a cada vez a experiências sensoriais imediatas.

A linguagem também permite ao homem a realização de operações dedutivas sem se apoiar nas impressões imediatas sem se limitar àqueles meios de que dispõe a própria linguagem.

Estas suas propriedades criam a possibilidade de existência das formas mais complexas do pensamento discursivo, o indutivo e o dedutivo, que constituem as formas fundamentais da atividade intelectual produtiva do homem. O silogismo é o modelo de pensamento lógico que se realiza com o auxílio da linguagem.

Os acentos, por exemplo, foram ignorados de um modo geral, mas podem ser transcritos em todas as palavras. Vigotsky, apud Cardoso, (2012, p.11) "Na visão de Vygotsky, a principal função da linguagem se constitui no intercâmbio social, pois a linguagem é o sistema simbólico básico dos grupos sociais". Ele apresenta em sua concepção que é na interação com o outro que acontece a comunicação.

Isto ocorre porque a transição do pensamento para a palavra tem que passar pelo significado e, como sempre, há algo oculto no que dizemos como: vontades, necessidades e 
emoções. A compreensão envolve o verbal e o não verbal, que só se encontram na interação com as pessoas.

O tema do pensamento e da linguagem situa-se entre aquelas questões de psicologia em que aparece em primeiro plano a relação entre as diversas funções psicológicas, entre as diferentes modalidades de atividade da consciência. O ponto central de todo esse problema é, evidentemente, a relação entre o pensamento e a palavra. Todas as outras questões conexas são como que secundárias e logicamente subordinadas a essa questão central e primeira, sem cuja solução não se podem sequer colocar corretamente as questões subsequentes e mais particulares (VYGOTSKY, 2010, p.19).

Entretanto, por mais alheio que pareça, a psicologia moderna não tomou ciência do enigma das afinidades interfuncionais, agente pela qual ele é moderno para ela. Tanto envelhecida como a própria psicologia, a tese do pensamento e da linguagem foi menos cogitada e prossegue mais sombria exatamente na paridade entre o pensamento e a palavra.

Ao decompor o pensamento discursivo nos elementos que o constituem e que são heterogêneos - o pensamento e a palavra -, esses estudiosos, depois que estudam as propriedades puras do pensamento como tal, independentemente da linguagem, e a linguagem como tal, independentemente do pensamento, interpretam a relação entre eles como uma dependência mecânica puramente externa entre dois processos diferentes (VYGOTSKY, 2010, p.37).

Pode-se nomear como exemplo as experiências de autores modernos, que buscam transformar o pensamento discursivo nos seus representados com o intuito de estudar a afinidade e a influência mútua entre esses dois processos.

O desenvolvimento dos conceitos científicos na idade escolar é, antes de tudo, uma questão prática de imensa importância - talvez até primordial - do ponto de vista das tarefas que a escola tem diante de si, quando inicia a criança no sistema de conceitos científicos. Por outro lado, o que sabemos sobre essa questão impressiona pela pobreza. É igualmente grande a importância teórica dessa questão, uma vez que o desenvolvimento dos conceitos científicos autênticos, indiscutíveis, verdadeiros - não pode deixar de revelar no processo investigatório as leis mais profundas e essenciais de qualquer processo de formação de conceitos em geral (VYGOTSKY, 2010, p.60).

Neste sentido, admira-se que um enigma que domina a tecla de toda a história da ampliação mental da criança e semelhava ser o tema de partida para o curso do pensamento infantil pouco tenha sido avaliado até hoje.

A linguagem interior é uma linguagem muda, silenciosa. Esse é o seu principal traço distintivo. Mas é precisamente no sentido do aumento gradual desse traço distintivo que se dá a evolução da linguagem egocêntrica. Sua vocalização declina até chegar a zero, ela se torna uma linguagem muda. Mas assim deve ser necessariamente se a concebemos como etapas geneticamente precoces no desenvolvimento da linguagem interior. $O$ tato de que esse traço se desenvolve 
gradualmente, de que a linguagem egocêntrica se isola antes em termos funcionais e estruturais que em termos de vocalização, sugere apenas o que tomamos por base da nossa hipótese sobre o desenvolvimento da linguagem interior, isto é, sugere que a linguagem interior se desenvolve através do enfraquecimento externo de seu aspecto sonoro, passando da fala para o sussurro e do sussurro para a linguagem surda e, através do isolamento funcional e estrutural, da linguagem externa para a linguagem egocêntrica e da egocêntrica para a interior (VYGOTSKY, 2010, p.75).

Para Vygotsky, o estudo da natureza psicológica da linguagem interior, com a aplicação do método que ousamos fundamentar experimentalmente, nos persuadiu de que a linguagem interior não deve ser afrontada como fala menos som, mas como uma locução discursiva categoricamente peculiar e incomum por sua armadura e seu funcionamento, que, em causa de ser composto em um plano categoricamente qualificado do plano da linguagem exterior, cultiva com esta uma indissolúvel harmonia ativa de modificações de um plano a outro.

Com isto, abordamos um aspecto na natureza da palavra, cujo significado ultrapassa os limites do pensamento como tal e em toda a sua plenitude só pode ser estudado em composição com uma questão mais genérica: a da palavra e da consciência. Se a consciência, que sente e pensa, dispõe de diferentes modos de representação da realidade, estes representam igualmente diferentes tipos de consciência. Por isso, o pensamento e a linguagem são a chave para a compreensão da natureza da consciência humana. Se "a linguagem é tão antiga quanto a consciência", se "a linguagem é uma consciência prática que existe para outras pessoas e, consequentemente, para mim", se a "maldição da matéria, a maldição das camadas móveis do espírito paira sobre a consciência pura", então é evidente que não é um simples pensamento mas toda a consciência em seu conjunto que está vinculada em seu desenvolvimento ao desenvolvimento da palavra (VYGOTSKY, 2010, p.77).

Pesquisas ativas mostram, a cada passo, que a palavra cumpre um papel essencial na consciência e não papéis encarcerados. Nela a palavra é justamente aquilo que é categoricamente excêntrico para um homem e plausível para dois. Ela é a demonstração mais direta da natureza histórica da consciência humana.

Através de palavras dotadas de significado a criança estabelece a comunicação com os adultos; nessa abundância de laços sincréticos, nesses amontoados sincréticos de objetos desordenados, formados com o auxílio de palavras, estão refletidos, consideravelmente, os laços objetivos, uma vez que coincidem com o vínculo entre as impressões e as percepções da criança (VYGOTSKY, 2010, p.79).

Assim, a criança se depara a cada passo no sentido das suas palavras com os adultos, ou melhor, a acepção da própria palavra na criança e no adulto repetidamente se atravessa até mesmo no componente palpável e isto é satisfatório para que adultos e criança se percebam.

Contudo, são bem distintas as passagens que induzem ao encontro do pensamento do adulto e da criança, e mesmo onde a significação da palavra infantil acontece parcialmente com a 
definição da palavra adulta isto procede psicologicamente de intervenções bem distintas e ocasionais, é fruto da combinação sincrética de representações que permanecem por trás da palavra da criança.

Dessa forma, a linguagem subsidia a aprendizagem e o desenvolvimento da criança na visão de Vygotsky, relacionando com o mundo, sendo preciso primeiramente ter a mediação de outras pessoas, isto é, o contato com os significados que possibilitam esta relação e assim a criança se apropria dessas relações desenvolvendo-se dentro da cultura que se encontra. É por isso que o homem criou funções, ferramentas que possam interferir no trabalho ajudando-o na resolução de problemas.

A função do instrumento é servir como um condutor da influencia humana sobre o objetivo de atividade; ele é orientado externamente; deve necessariamente levar as mudanças nos objetos; constitui um meio pelo qual a atividade humana externa é dirigida para o controle e domínio da natureza; o signo, por outro lado, não modifica em nada o objeto da operação psicológica; constitui um meio da atividade interna dirigido para o controle do próprio individuo; o signo é orientado internamente (VYGOTSKY, 1989, p. 62).

O desenvolvimento para Vygotsky acontece por meio da mediação do homem e sua cultura na qual é fundamental no comportamento e responsável pelas mudanças que ocorrem, e a criança assimila essas experiências dando a oportunidade para que a aprendizagem se desenvolva esta que já é existente na criança.

Sendo assim (Vygotsky apud REGO, 2001, p. 55) “(...) especialmente a linguagem, funciona como elementos mediadores que permitem a comunicação entre os indivíduos, o estabelecimento de significados compartilhados por um determinado grupo cultural (...)”.

Para o autor acima citado a interação social tem uma enorme importância e grande contribuição no desenvolvimento humano, de acordo com o mesmo o desenvolvimento da criança depende de um processo de maturação do organismo como um todo e em seguida a interação da criança com sua cultura.

Vygotsky (2001) afirma que uma pessoa quando "isolada ou privada do contato com outros seres, apenas com suas próprias condições a favor da dos recursos da natureza p homem é fraco e insuficiente".

O desenvolvimento esta intimamente relacionado ao contexto sociocultural em que a pessoa se insere e se processa de forma dinâmica ( e dialética) através de rupturas e desequilíbrios provocadores de contínuas reorganização por parte do indivíduo (VYGOTSKY, APUD REGO, 2001, p. 58).

De acordo com o autor acima o aprendizado é considerado a presença necessário e se faz essencial no processo do desenvolvimento, de maneira que garanta as características psicológicas e humana organizadas culturalmente, sendo assim o desenvolvimento depende do aprendizado 
que acontece em um determinado grupo cultural, a partir da interação com os outros indivíduos de sua espécie, (Vygotsky, apud Rego, 2001, p. 71) “a criança só aprendera falar se pertencer a uma comunidade de falantes, ou seja, as condições orgânicas, possuir aparelho fonador, embora necessárias, não são suficientes para que o indivíduo adquira a linguagem”.

Existem dois níveis de desenvolvimentos que são fundamentais na construção do conhecimento infantil e para a aprendizagem esta que já acontece muito antes da criança frequentar a escola, esses níveis Vygotsky chamou de "brotos" ou "flores" do desenvolvimento.

O nível de desenvolvimento real ou afetivo pode ser entendido como referente àquelas conquistas que já estão consolidadas na criança, aquelas funções ou capacidades que ela já aprendeu e domina (...). O nível potencial ou proximal também se refere àquilo que a criança é capaz de fazer, só que mediante a ajuda de outra pessoa adulta e crianças mais experientes (VYGOTSKY, APUD REGO, 2001, p. 72-73).

Os signos foram fundamentais no processo da evolução do homem, isto é, contribuiu no desenvolvimento psicológico, auxiliaram na memória e para a formação do seu bom comportamento em sociedade, fazendo com que este tenha o domínio de si para a boa uma conduta.

Tenreiro Et Al (2009, p.93) diz que "a mediação da linguagem possibilita, aos novos indivíduos de um dado grupo social, a apropriação, desde cedo, das formas de perceber e organizar o mundo, como um filtro interposto entre o homem e a realidade".

A partir do momento em que a criança começa a utilizar esses signos e entender que eles servem para auxilia-las no seu desenvolvimento e que podem contribuir no avanço da sua aprendizagem, estes se mostram mais interessados em fazer o seu uso se forma correta.

Quando a criança passa a utilizar a fala e os signos (amarrar um cordão no dedo para lembrar de algo ou usar um código para trazer ideias), produz-se uma modificação em suas funções psicológicas superiores. Se a fala e os signos são incorporados a qualquer ação, esta ação se transforma e se organiza de forma totalmente nove (TENREIRO, Et Al, 2009, p.94).

Dessa forma, pode-se entender que para que ocorra o desenvolvimento significativo na vida da criança é preciso de mediadores, isto é, mais que uma pessoa, para que ocorra o seu desenvolvimento individual.

Como diz Tenreiro Et Al, apud Oliveira (1993, p. 60) “é como se um processo de desenvolvimento progredisse mais lentamente que o processo de aprendizado; o aprendizado desperta processos de desenvolvimento que aos poucos vão tornar-se parte das funções psicológicas do individuo". 
É como diz Vygotsky o aprendizado deve estar à frente do desenvolvimento, assim ele contribui no papel de puxá-lo para fazer acontecer, contando então com a implicação pedagógica esta, que tem a grande importância na vida dos indivíduos, pois os professores entraram como mediadores, através da linguagem e de suas implicações pedagógicas proporcionando o suporte e a interferência, para que o aluno possa transformar suas funções mentais em realidade com autonomia.

\footnotetext{
Vygotsky que o único bom ensino é aquele que se adianta ao desenvolvimento. Com essa afirmação, ele valorizou sobremaneira a intervenção pedagógica: as instruções dadas pelos professores, as demonstrações, a assistência oferecida aos alunos na resolução de problemas, o fornecimento de pistas indicativas. Para ele, o que o sujeito consegue fazer com ajuda de alguém, amanha ele fará por si (TENREIRO, Et Al, 2009, p. 95).
}

Segundo o autor acima, seu comentário é de fato muito importante, pois, ele ressalta que o bom ensino aquele que traz rendimentos a aprendizagem, esse deve estar adiantado do desenvolvimento, onde quem vai colaborar com o resultado esperado.

Dessa forma, é por meio do professor e do seu entendimento e pela sua mediação ele fornece instruções e uma boa assistência para que os alunos sejam capazes de resolver os problemas propostos e fazer com que aquele indivíduo que hoje precisa de ajuda amanha estará realizando por si só.

\section{Considerações Finais}

Essa pesquisa enfatizou a construção da linguagem e do pensamento da criança problematizando conhecer como se processa o desenvolvimento da linguagem e do pensamento infantil, com o objetivo de conhecer e ampliar os estudos referentes ao tema, a fim de melhorar o ensino e aprendizado da criança.

A linguagem e o pensamento são funções sociais pertencentes à espécie humana. Desde o seu nascimento o homem vem aprimorando as suas formas de comunicação como meio de sobrevivência, principalmente quando se trata da inserção no mercado de trabalho, onde ele necessita dos mais variados tipos de interação com as pessoas.

Assim, ao investigar como a criança adquire seu potencial para a comunicação com o meio externo na relação com as pessoas que a cerca pode promover um paralelo entre os teóricos que enfatizam o pensamento e a linguagem, identificando igualmente, os diversos tipos da linguagem que ampliam a construção do pensamento infantil.

Pode-se analisar a linguagem como ferramenta de mediação com o meio externo e conhecer os meios que o professor utiliza na construção do pensamento infantil. Dessa forma, a linguagem deve ter, em sua formação inicial, clareza de seu importante papel. 
Do mesmo modo, espera-se que o alcance desta pesquisa seja agente de apoio aos professores e interessados na busca de minimizar as dificuldades de aprendizagem.

Sendo que a aprendizagem por transmissão social é que possibilita ao homem avançar no desenvolvimento de suas potencialidades e tudo o que o sujeito faz hoje, com o auxílio e orientação do outro, amanhã poderá fazê-lo de forma independente. Por isso que se fala em socialização do conhecimento.

Daí a importância da linguagem, dos símbolos e da cultura no processo de humanização deste aluno. Portanto, desenvolvendo as capacidades superiores da criança no sentido de ao se transformar, se humanizar, para que ela possa dar sua contribuição para que este processo ocorra também com outros seres humanos.

\section{Referências}

CARDOSO, Bruna Puglisi de Assumpção. Práticas de linguagem oral e escrita na educação infantil. São Paulo: Anzol, 2012.

COLE, Michael; JOHN-STEINER, Vera; SCRIBNER, Sylvia; SOUBERMAN, Ellen. Introdução. In: VYGOTSKY. A formação social da mente: o desenvolvimento dos processos psicológicos superiores. Tradução José Cipolla Neto, Luís Silveira Menna Barreto, Solange Castro Afeche. 6.ed. São Paulo: Martins Fontes, 2003. p.1-19

DRANKA, Renata Aparecida Paupitz., Linguagem como Mediação entre a vontade do Eu e do Outro in Revista Linguagem em (Dis) curso, volume 1, número 2, jan./jun. 2001 disponível em: http://www3.unisul.br/paginas/ensino/pos/linguagem/0102/05. Acesso em 27/06/2018.

LEONTIEV, Alexis Nikolaevich. O desenvolvimento do psiquismo. tradução de Manuel Dias Duarte, Lisboa: Livros Horizonte, 1978.

LURIA, Alexander Romanovich. Introdução Evolucionista à Psicologia: Curso de Psicologia Geral. Rio de Janeiro: Civilização Brasileira, 1979. v. 1.

LURIA, Alexander Romanovich. «Vygotsky», in: L. S. VYGOTSKY, A. R. LURIA e A. N. LEONTIEV. Linguagem, desenvolvimento e aprendizagem. SP: Ícone. 1988.

LURIA, Alexander Romanovich., LEONTIEV, Alexis Nikolaevich. e VYGOTSKY, Lev Semenovitch. Psicologia e pedagogia: bases psicológicas da aprendizagem e do desenvolvimento. São Paulo: Moraes. 1991.

OLIVEIRA, Marta Khol. Vygotsky: aprendizado e desenvolvimento - um processo sóciohistórico. São Paulo: Spione, (Série Pensamento e ação no magistério). 1994.

OLIVEIRA, Marta Khol. de. Vygotsky: aprendizado e desenvolvimento: um processo sóciohistórico. São Paulo: Spicione, 1997.

OLIVEIRA, Marta Khol. Vygotsky e o processo de formação de conceitos. La Taille, Yves de.; Oliveira, Marta Khol de.; Dantas, Heloysa. Piaget, Vygotsky, Wallon: teorias psicogenéticas em discussão. São Paulo: Summus, p. 23-34. 1992.

REGO, Teresa Cristina. Vygotsky: Uma Perspectiva Histórico-Cultural da Educação. 13a edição. Petrópolis: Vozes, 2001. 
TENREIRO, Maria Odete Vieira., BERGER, Maria Virgínia Bernardi., LAROCCA, Priscila.; MORO, Neiva de Oliveira. Licenciatura em Pedagogia: Psicologia da Educação. Ed.UEPG, Ponta Grossa, 2009.

VYGOTSKY, Lev Semenovitch.; LÚRIA, Alexander Romanovich.; LEONTIEV, Alexis Nikolaevich. Linguagem, desenvolvimento e aprendizagem. Tradução de Maria da Penha Villalobos. São Paulo: Ícone, 1988.

VIGOTSKI, Lev Semenovitch. A construção do pensamento e da linguagem. Tradução Paulo Bezerra. São Paulo: Martins Fontes, 2001.

VIGOTSKI, Lev Semenovitch. Pensamento e linguagem. Tradução Jefferson Luiz Camargo. 2.ed. São Paulo: Martins Fontes, 2003a.

VIGOTSKII, Lev Semenovitch. e LURIA. Alexander Romanovich e LEONTIEV, Alexis Nikolaevich. tradução VILLALOBOS M. da P. Linguagem, desenvolvimento e aprendizagem. São Paulo, Editora: Ícone. 2001.

A formação social da mente: o desenvolvimento dos processos psicológicos superiores/ L.S. Vigotsky; organizadores Michel Cole... [et al.]; tradução: José Cipolla Neto, Luís Silveira Menna Barreto, Solange Castro Afeche. 7.ed. - São Paulo: Martins fontes, 2007. . Psicologia Pedagógica. 3.ed, São Paulo - Editora WMF Martins Fontes, 2010. 